\title{
Determinants of Turn-Taking in Nigerian Television Talk Shows
}

\author{
Olutayo, Omolara Grace ${ }^{1, *}$ \\ ${ }^{1}$ Department of English, Faculty of Humanities, Bowen University, Iwo, Nigeria \\ *Correspondence: Department of English, Faculty of Humanities, Bowen University, Iwo, Nigeria. \\ E-mail: graceolutayo@yahoo.com
}

Received: May 19, 2013

doi:10.5430/wjel.v3n3p67
Accepted: July 2, $2013 \quad$ Online Published: September 20, 2013

URL: http://dx.doi.org/10.5430/wjel.v3n3p67

\begin{abstract}
Previous researches on media studies in Nigeria have not given the language of television discourse adequate attention. The print media seem to have had more admirers than the broadcast media. This paper therefore attempts to fill this gap by examining natural conversations in television discourse. It investigates the determinants of turn-taking patterns in Nigerian television (TV) talk shows. Three popular Nigerian TV talk shows were purposively selected for the study; four episodes bothering on different topics were selected from each talk show and recorded on video cassettes via the television. Our findings revealed seven main determinants of patterns and features of turn-taking namely: discourse topic, duration of the programme, composition of the guests/participants, culture, social status, gender and the personality of the hosts. These revealed the nature of the show and participation, floor occupation, shared understanding, turn quantification and emotiveness.
\end{abstract}

Keywords: turn-taking patterns; television talk show; conversation analysis

\section{Introduction}

The language of television discourse in Nigeria has not enjoyed enough attention from researchers as other genres such as courtroom discourse (Onadeko, 1999) doctor/patient interaction (Odebunmi, 2003), and the print media (Chiluwa, 2005; Taiwo, 2008), political discourse (Oyeleye \& Osisanwo, 2013). Olutayo (2010) and Oyeleye \& Olutayo (2012) did an extensive work on the linguistic analysis of Nigerian television talk shows. This research is a continuation of these previous works on Nigerian television discourse. It investigates the factors determining the patterns of turn taking in the talk show genre.

\subsection{Television Talk Shows}

Television talk show in Nigeria has recorded a rapid growth in the recent times and with this growth there arises a need to carry out a linguistic study which will provide a forum for comparison with TV shows outside the shores of the nation. According to Mikos (1996) and Bente and From (1997), talk shows are regarded as highly personalized and emotionalized programmes. Critics also observe that features of talk shows include extreme and socially undesirable opinions, bizarre behaviour and social deviance; bad language, fighting, confrontations, and even physical force as means of interpersonal communication and problem resolution. They do not proffer solutions to problems but leave most conflicts unresolved. It has also been claimed that they are mainly oriented toward sexuality and the depiction of sexual preferences; and present the exception as the ordinary, which may lead to a misperception of reality and an immunity of regular viewers to other people's misfortune (e.g. Plake, 1979; Graf, 1998).

These criticisms are very similar to points made by U.S. scholars who studied the influence of daily talks on viewers. They express concern that programmes make the abnormal seem normal, desensitize viewers to human suffering, cause suffering, cause viewers to trivialize complex social issues, and fail to offer solutions in most cases and that younger viewers may be more susceptible to these effects ( Brinson \& Winn, 1997; Davis \& Mares, 1998).

However, it is important to note that most Nigerian television talk shows do not share these features. Nigerian TV talk shows like their counterparts all over the world have their peculiar characteristics as determined by their hosts and the culture/environment in which they are aired (Olutayo, 2010). They are often employed as tools of awareness campaign, enlightenment, problem solving, and entertainment. We hardly have shows with vulgar expressions and fights. Instead of programmes on fighting, bizarre behaviour, bad language, and sexuality, Nigerian talk shows are more concerned 
with re-orientating Nigerians, influencing their opinions as regards government policies and societal issues. This difference in features also implies that patterns of turn-taking in Nigerian TV talk shows are determined by varying determinants which would definitely differ from those of the western world.

Grindstaff (2002) distinguishes between 'classy' and 'trashy' talk shows, this distinction shows what types of stories they portray, the kinds of guests they attract, and how they attempt to manipulate those guests in order to produce emotional moments in the pursuit of 'good television'. She uses a pornography term as a metaphor to explore the multifaceted ways talk show producers and guests function within the confines of mediated talk programs while attempting to achieve the 'money shot', or moment of emotional truth performance that create a highlight within the show. Her ethnographic approach to the study, grounded in theories about feminist fieldwork, allows for a particular analytic style in which some of the producers of these cultural artefacts are able to speak for themselves. One of the most successful elements of this study is that it creates a new way of understanding how and why talk show guests decide to air their dirty laundry on television. She also examines how the process of 'fluffing' or preparing them to perform emotionally, interacts with the structure and intent of these shows to create a particular idea of 'ordinariness'. The study also acknowledges that the guests are active participants and not merely dupes being exploited, without ignoring the social power dynamics that make certain people more likely to appear on shows than others. Grindstaff critiques the way that talk shows often simplify huge social issues for the sake of creating easily digestible sound bites. While Grindstaff's analysis provides a good understanding of how and, in some cases, why talk shows and their guests are configured in a certain way, there are also elements of her study that could have been improved or altered to provide a more broad image of talk show, production and how images are manipulated in order to achieve the aim of the show.

Hamo (2006) draws on the semi-institutional perspective in analyzing discursive power relations by examining how talk show guests' social roles and status affect the dynamic balance between elements of institutional and natural discourse. Using quantitative analyses of three measures, his findings reveal that anonymous guests take fewer turns, intervene less and self-select less than famous and semi-famous guests on the show. He also uses qualitative analysis to reveal a dialectal response by the host to anonymous guests' initiative behaviour. Our study however, differs as our focus is on the factors responsible for the participants' conversational behaviour.

\section{Turn and Turn Taking}

Ervin Goffman (1967: 270-271) refers to a turn at talk as "an opportunity to hold the floor, not what is said while holding it”. Though most researchers use the terms turn and floor interchangeably, Edelsky (1981:209) maintains that the concept of floor correlates with "the acknowledged what's-going-on within a psychological time/space". A floor may therefore consist of several turns, just as it is possible to take a turn without having the floor (through interruption). According to Edelsky (1981), two or more participants often took part in an apparent free-for-all or jointly built one idea, operating on the 'same wavelength'(ibid: 384). This indicates that several participants may jointly hold the floor in two different ways by engaging in simultaneous talks, jointly building an answer to a question, collaborating on developing ideas and sharing laughter. In less 'unorderly' stretches of talk, Edelsky found that participants, though speaking sequentially, shared "in the creation of an idea or a function (joking, suggesting, etc.)." (ibid: 393).

Although turn-taking mechanisms seem to be universal, they are subject to cultural and institutional variations as we have discovered in this work. Traditionally, turn taking refers to turn switches where speaker B takes over after speaker A relinquishes the floor, overlaps, backchannels and interrupts. However, daily conversations are filled with syntactically incomplete or ill-formed utterances which make it difficult for speakers to decide when to take turns (Hua-Li\& Wu, 2011). Turn-taking behavior has been related to socially correlated externals. Existing research suggests that social role, age, gender, education, and background culture (Laskowski et al, 2008; Berry, 1994); dialogue type ( Bosch et al, 2004) topic (Laskowski et al, 2004), or familiarity among speakers ( Jaffe et al, 2001) all impact turn-taking behavior. Lui Jia (2010) in her research "indicates age, gender and class as possible factors affecting women conversational style. Our focus in this paper is to identify the main determinants of turn taking patterns in the TV talk show genre.

\section{Methodology}

Three popular and well-established Nigerian television talk shows were purposively selected for this study. They are: "Patito's Gang” (henceforth to be referred to as PG), "New Dawn” (ND) and "Inside Out” (IO). For ease of analysis four episodes with varieties of subject matters were selected from each show and they were numbered accordingly. The qualitative method of analysis was adopted to study the determinants of the features and patterns of turn-taking 
observed in the selected talk shows. Recorded episodes were played several times to identify the determinants.

\section{Analysis}

So many factors contribute to turn-taking patterns in TV talk shows. These factors are referred to as determinants of turn-taking in this study. In this paper, we identified seven main determinants namely discourse topic, the personality of the host, composition of guests, studio audience, duration of the programme, social status of the participants, gender and culture. These determinants are discussed one after the other below:

\subsection{Discourse Topic}

The topic of a particular TV talk show determines to a large extent the patterns and features of turn-taking in that show. While some topics are highly controversial and interesting, others are just by the way; that is, they may not be quite interesting and current. The controversial ones get all the support and involvement that is available. The host, the guest and even the studio audience are excited and desire to have the floor at any available opportunity to make their points. This accounts for the reason topics like 'State of Emergency' (PG1), 'Physical Challenges' (PG3), 'Abuja' (PG4), 'Global Warming' (ND1), 'Fan's Mails' (ND2), 'How safe are we?' (IO1) and 'No Romance without Finance' (IO4) enjoyed more guests' and audience participation than others. There were not too many long turns in these episodes as all the participants wanted a piece of the action. Therefore, more interruptions and overlaps were recorded in these episodes than in others. In fact, out of the topics listed above, PG1 and IO4 had more instances of interruptions and overlaps.

The nature of PG1 at that time called for a lot of controversy. It was about a government policy that 99\% of Nigerians frowned at and so as the discussion held, the participants found an avenue of venting their anger on the government by raising their voices and attacking the government. No one out of the 'gang' and even the members of the parliament at the 'Village Square' agreed with the decision. There was even a turn by a participant urging Nigerians to declare a state of emergency on the then Nigerian President who took such an unpopular decision. One could conclude through this outburst that this show felt the pulse of the nation at that time and so the participants spoke the minds of Nigerians.

IO4 was titled 'No Romance without Finance'. This was and still is a hot topic among the youths and even the elderly. Many of the interlocutors believed that romance and finance were inseparable; others held the view that money was not a necessary ingredient for romance. Just as in PG1 discussed above, the floor was hotly contested for by the guests and participants. Several of the contributions were not clear as guests resorted to a shouting match in order to make their points. At these moments, it was the guest whose voice was the loudest and who had access to the floor that could be heard. This topic had more overlaps and interruptions than even PG1. Some contributions were inaudible due to the fact that everybody wanted to talk at the same time. The studio audience too were much more involved than they were in other episodes. The host had a lot of trouble bringing the discussion under control, taking a break and closing the discussion. It was a very controversial topic.

PG3 and ND1 had similar features though they were also topical issues, they did not generate a lot of debate as did PG1 and IO4. The guests and studio audience were fully involved in the discussion. PG3 was on Physical Challenges. It was a current issue at that time too but it was more of an enlightening programme rather than a debate; therefore, there were not as many contests for the floor as we had in PG1. ND1 was also an awareness programme. The studio audience and viewers at home were enlightened on the need to plant trees in their environments. Most of the interruptions recorded were from the host while seeking clarifications from the guests.

\section{Excerpt 1-ND1}

PP1: Well(.) climatic condition do change naturally and hem (sic) the atmosphere and nature has its own mechanism of adapting to such changes but when the changes are becoming extreme then, it becomes difficult for the system, the natural ecosystem and atmosphere to actually hem adapt to the situation. What, it is happening not only in our Atlantic Ocean Bridge but in many other part of the world, due to issues of changes in temperature of the earth...

TH: $\quad$ So called global warming?

PP1: Global warming; and is due to hem you know extreme concentration of certain gases known as greenhouse gases that are you know released to the atmosphere due to human industrial production you know human use of resources and sometimes the gradulation (?) of the environment you know like removal of oil, burning of oil, burning of forest and this has implication on a lot of natural ecosystems as you have mentioned. Let's take the issue of coastal areas because in many countries outside Nigeria, in 
the temperate regions; the height of glacier gets melted because the temperature of the world rise may be between ah ah $0.2^{\circ}-0.6^{\circ} / 0.8^{\circ}$ Celsius in the past ten - fifteen years. Scientists have confirmed that temperature rise is becoming prominent and ...

TH: $\quad$ So, the world in the past ten years the world has become warmer...

Due to the nature of the excerpt above, there was no need to debate any issue; it was purely an enlightenment show thus accounting for the presence of cooperative interruptions.

PG4, ND2 and IO1 could be said to belong to the same category. They included some debates and opinionated contributions. We also had some contests for the floor. PG4 and IO1 were timely topics. PG4 was on restoring Abuja to its original plan. At that time, most Nigerians were not happy that houses were being demolished and people were displaced. There was therefore, the need to clarify issues-whether the demolition exercise was actually meant to restore the aesthetics of Abuja or that it was done out of the desire to oppress. While PG4 had 69 instances of interruptions, ND2 had 13 and IO1 had 23.

IO1 was on the security of Nigerians. This was another controversial topic although it was not as controversial as IO4. The Police Public Relation Officer was part of the invited guests. In his bid to protect the image of the Nigerian Police, he struggled to get the floor and held onto the floor more than the other participants. We also recorded a good number of interruptions (23) and overlaps (6) in this topic.

\subsection{The Personality of the Hosts}

The hosts in our data differed in their characteristics as they attempted to fulfil their roles. Professor Pat Utomi (in PG) was the most vibrant of them all. He was revolutionary in his presentations. While moderating the conversations, he provided the participants with more opportunities to take the floor unlike Funmi Iyanda (in ND) who was too overbearing in her shows. Her domineering attitude is a reflection of gender difference arising from the way the society treats women. We see Funmi in her show striving to assert her role as the 'owner' of the programme who dictated the tune. She asserted her authority effectively. The guests no matter their status had to toe her line. The studio audience was also not left out. In ND3, the only response we got from the studio audience was applause for the governor and a prompted 'thank you' at the end of the show. Out of the 114 turns, Funmi had 56 while the supposed studio audience had 2. In ND2, while the host had 93 turns; the studio audience had only five. She exhibited an absolute authority over them. Participants only talked when they were prompted, thus making for fewer interruptions and overlaps in her shows. However, in ND1 and ND4 more opportunities were given to the studio audience to contribute to the discussion. The studio audience had 10 turns in ND1 and 4 in ND4

Agatha Amata (in IO) was almost like Pat Utomi (in PG). However, she moved around with a mobile microphone giving the studio audience opportunities to contribute. Although she was not as domineering as Funmi, she was an efficient moderator. In fact, she did not sit with the guests but stood in the middle of the hall where the studio audience sat. Agatha walked amidst the studio audience throughout the thirty minutes show with a microphone in her hands. This position illustrated the intimacy between the host and the studio audience; it also showed Agatha's concern to involve the studio audience in the proceedings and to solicit their opinions, feel the pulse of the discourse and exercise restraints where necessary; she was also able to select the next speaker from the audience and where self-selection occurred; she decided who took the floor.

\section{Excerpt 2-IO4}

19. PP1: He is talking of only a type of people (.) there is only one type of people who talk like this (.) they, they live in their heads, they are distinctive thinkers(.) knowledge seeking people.

20. TH: Okay, okay let me take comment, please if you have any comment just put up your hand and then I'll, I'll take it. (Studio audience signify their intention to speak by raising their hands and she calls on one of them).

21. SA1: When a woman describes a man, she describes from two perspectives: one, the man is rich, the man is romantic, it's either he is rich or he is what? Romantic because we have had situations where a rich girl like this lady, later the woman said that man has money but he's not what? Romantic. So there's nothing that has to do with money that is romantic, so if somebody is romantic it has nothing to do with money.

This excerpt illustrates where TH gave opportunity to the studio audience to air their views. She had to stop the participants to make room for the studio audience. This act indicates the importance that Agatha placed on her studio audience. They were not just there to fill spaces but their views were also considered to be important. After this speaker, there were about 13 turns by the participants, but the host (Agatha) still went back to the studio audience for their own 
contributions.

The way the hosts presented the topic also determined the responses from the participants; social and political topics were presented in such a way as to encourage disagreement which often led to debates. For example, PG1, PG4, IO1, IO4 were presented by the hosts to generate controversy among the participants:

\section{Excerpt 3-PG1}

1. TH: Plateau state legislature first went into stupor before realizing they have been denied their right. The governor, instead of standing up for his office and right went into a long...the issue of religion; ethnicity and citizenship would not go away if we do not apply the constitution.

2. PP1: Until we have a sovereign national conference we cannot have an autonomous and...

3. TH: Now, how did we get to the state of emergency? What really come to cause this situation?

4. $\quad$ PP2: $\quad$ Em.... let me start by describing that em... by saying that em... there wasnothing that called for a state of emergency in Plateau state. Secondly, that the propriety of the action is fundamentally flawed and questioned. Thirdly, that the legal regime in terms of our constitution expectation does not permit what Mr. President had done...

The presentation of the host in turn 1 and 3 in the excerpt above was meant to stir up a controversy. His choice of expression such as 'went into stupor before realizing they had been denied their right' was enough to awaken the participants who might have not known where to start the discussion from.

\section{Excerpt 4-IO1}

1. TH: Hello, you are welcome once again to another episode of 'Inside Out'. This week we have the topic that concerns every Nigerian no matter who you are or where you are from. I like to believe so. It has to do with the security of the nation...

2. PP1: Considered, you discover that, every member of the public is a stake holder in the security business, security affair, if you leave it to the police alone, you discover that we might do a little and it might not be appreciated. And in doing this task in the police...

3. PP2: ...the same to the president based on section 33 that everybody has equal right and that nobody's life is to be gunned like that without any pictures...

The opening here too was meant to stir up the interests of the guests, the studio audience and the viewers. Security in the country at that time was a very sensitive issue which everybody as TH stated would want to contribute to. The choice of the expressions- "no matter who you are or where you are from" was deliberate and the intention was to get the participants ready for the discussion.

The hosts (Pat, Funmi and Agatha) opened the talk by wetting the appetite of the guests and the viewers, managed the discussion effectively and closed the talk with summaries of all the points discussed while urging viewers to look forward to more.

\subsection{Composition of the Guests}

The composition of the participants differed from one talk show to the other. The guests on PG were classified into three because the show itself had three aspects- the 'gang', the 'village square' and the 'Bull's Eyes'. The 'gang' was always made up of five professionals and highly placed people in the society including the host. Sometimes, we had a mixture of both sexes but the gang in PG1 was made up of only male participants. In the 'village square' we had about 25 youths (male and female) who were probably laymen or upcoming professionals and the 'Bull's Eyes' had just the host and a guest (a specialist in the area of discourse). While PG was made up of intellectuals, and professionals who had made their marks in their various fields of discipline such as Rueben Abati, a renowned journalist, Olisa Agbakoba, Mike Ozekhome, Professor Itse Sagay, constitutional lawyers, Oby Ezekwesili, a former minister of education, Mallam El Rufai, former minister of the Federal Capital Territory, Dr. Osakwe and the likes, the composition of the guests on the other two shows was not as intimidating as that of PG. ND was more of interview sessions. We had the Governor of Lagos State, Director, Technical Programmes Conservation Foundation, Conservation and Events Officer, Professor Wole Soyinka and a columnist. IO was also made up of intellectuals and highly placed people like Lagos State Commissioner for health, Lagos State Police Public Relation Officer, Dr. Veraola Okoli (a specialist in Special Education) and others. However, Agatha did not always have the same set of guests as did PG. She composed her guests as the need arose. Sometimes, the guests could be made up of youths and laymen.

The choice of participants determined the credibility of the discussions. The viewers would have more confidence in 
participants who have something to offer. ND had celebrities and a few professionals (between one or three guests on each show). IO had both laymen and professionals (about six, both sexes) depending on the topic of discourse. The sitting position of the guests distinguished them from the studio audience. They were seated facing the audience thereby drawing more attention to themselves and their discussions. Each of them had a microphone pinned to his/her chest to aid voice projection. In IO, the guests were seated on a raised platform facing the studio audience mainly made up of youths. The first session of PG (the gang) had no studio audience; the guests spoke directly to viewers at home. The implication of this is that discussions in the first sessions of PG were only amongst the guests; there was no opportunity for immediate feedback from the studio audience. However, the second session referred to as the Village square was made up of the studio audience and the moderator excluding the guests. It was like an open discussion floor where everybody was given a room to air his/her opinion. PG then had a peculiar format clearly different from other talk shows.

\subsection{Duration of the Talk Shows}

The period in which a show is aired also contributes a lot to the features and patterns of turn-taking. A topic which has a current bearing on what is happening in the nation or within a particular group in a community would enjoy more participation and support from the participants. The timeliness of the topic would provide fresh contributions and illustrations from participants who would want the viewers and their fellow discussants to hear them out. Thus, there were more contests for the floor in current topics than in others who were just part of the problem the society constantly faced.

PG1 was aired in May, 2004. At that time; the Nigerian government had just declared a state of emergency on Plateau State. The decision was still fresh in the minds of Nigerians and so the participants were eager to make their feelings known. Some of them were still angry at the government for taking such a decision without consulting the National Assembly and the Nigerian populace. Similarly PG2, PG3 and PG4 were current issues when they were aired. PG2 held when the Association of Radiologists in West Africa (ARAOWA) was preparing for its national conference whose aim was to create awareness within the government circle and among Nigerians about the role and importance of radiologists in the nation's medical system.

PG3 came at a time when there was clamour for more recognition for the physically challenged. The minds of Nigerians were being orientated towards this; therefore, the participants were all interested in the discourse. PG4 was also aired when the controversy over the demolition of houses and other buildings in Abuja was high. This made the programme to equally enjoy good support from the participants. The topic also dictated the choice of the special guest to be invited to the 'Bull's Eye' section where the host interviewed the then Minister of the Federal Capital Territory.

In IO1, the duration of the programme had more effect on guests' participation than others. It was at a period when every Nigerian felt insecure, when everybody was scared of transacting business in commercial banks. The other guests and the studio audience were therefore at alert and very active during the discussion. Some of them even condemned the Nigerian Police. They advocated private security outfits.

\section{Excerpt 5-IO1}

1. TH: Em... let me talk to Emma (.5) what is your view? How safe do you think we are?

2. PP5: Em... in Nigeria, haa... I don’t believe we are absolutely safe (.3) I don't even believe we are 50\% safe in this country. My point is that insecurity is something that has got to do with haa... that has its platform with every individual life and ha if we define it we discover that truly Nigerians we are not safe because it's a world that has got to do with=

3. TH: Okay am going to ask you a question which I haven't asked before (.3) okay let me just take it to you. Do you think it's possible that you cannot rely solely on the police force that we ourselves are lacking in something even the attitude of the average Nigerian to security is large do you think so?

4. PP5: I believe that...

From the response of PP5 in turns 11 and 13, we observed the excitement in his voice and the eagerness to make his views known. This suggests the importance and timeliness of the topic of discourse.

\subsection{Social Status}

Social status plays an important role in the performance of interlocutors in talks. To a large extent it determines the number of turns a participant can take. It also dictates how often a speaker can be interrupted. Participants with higher status, that is, those who occupy a higher rank in the social ladder tend to dominate talks more. In fact, they tend to interrupt more and the other participants in deference to their age and status avoid interrupting them when they speak. 
Such dominance of the conversational dynamics is popularly associated with higher status or leadership role. The PPRO in IO1 perfectly fitted into this description. He used his status and his professional expertise to dominate the discussion; out of the 9 turns he took in the discussion, 7 were through interruptions.

In PG, participants in the 'gang' were of the same social status; therefore, there were no instances of one participant dominating the discussion because of his status. However, a participant may dominate a discussion because of his professional expertise as we had in PG1 where Mike Ozekhome, a constitutional lawyer had more (longer) turns than the other interlocutors. The 'village square' also enjoyed the same status as the host who was the one on a higher status brought himself to the same level with the participants. It was only in the 'Bull's Eye' section that status was brought into play. There was obvious deference for age and social status in turn exchanges. Pat Utomi was not the one who took the 'Bull's Eye' section of PG1. It is assumed that his assistant did. The interview with Professor Itse Sagay was devoid of any interruption or overlap. The status of the renowned constitutional lawyer must have intimidated the young man as he allowed Sagay to finish his contributions before taking the floor. It was more of a question and answer session rather than a discussion.

\section{Excerpt 6-PG1}

152. TH: Thanks for joining us again as we meet Professor Itse Sagay, a constitutional lawyer and we tackle the State of Emergency. Thanks for joining us on the programme Sir.

153. PP: You're welcome

154. TH: We have a crisis in a particular area of Plateau. And a State of Emergency was declared in the whole state. What was your first impression on hearing of it?

155. PP: Yes (.) I must confess that I was surprised em... at that because of the limitation, the limited area in which the crisis you know was taking place. I understand 2 or 3 out of 17 local governments in the state. And I thought that... those... that area was so small that our security agency should have been able to bring quiet to it without going to such extreme measures.

156. TH: Well, as a constitutional lawyer, was such an act really constitutional? We we've had a debate going back and forth on the legality of the action itself. Does the president have such power?

157. PP: Well, there are two rights (.3) you're talking of either legal right or moral right or political right. On a legal aspect, he was entitled to because em... the constitution gives some discretions to the President to determine what he regards as a sufficiently serious state of a threat to public peace and order and also to determine what area is it because the constitution sees simply says the...

One would have thought that the host would have interrupted the guest at a point in the discussion; especially, in the middle of turn 155, where he mentioned the number of local governments involved in the crisis but he did not. He waited until he finished his turn. The implication of this is that the social status and the age of PP must have kept TH from interrupting. Another reason would be culture, most Nigerian cultures do not permit a younger man to speak when an elder still has the floor.

In PG4, where Pat interviewed the then minister of the Federal Capital Territory in the 'Bull's Eye' section, there were also no instances of interruption or overlaps. All the turns there were complete grammatical units. The minister at that time was more highly placed than the host; the host was therefore compelled to accord him the respect he deserved. This is purely a Nigerian factor; in most cultures in Nigeria, respect is held in high esteem and our leaders take their time to exploit this as they are like lords in their various offices. Thus, the host's questions were carefully framed so as not to incur the wrath of the minister:

\section{Excerpt 7-PG4}

141. TH: Now, talking about reclaiming the city itself. How far reaching are your actions in reclaiming the city and returning to the master plan? How far reaching has it been?

142. PP: Well, em... in terms of breadth, I will say it's very broad because we have ah tried to touch everybody. We started with the city where the elites have their mansions and we've taken so many high profile buildings down eh... e... to retrieve the master plan in the first phase. Ah in the subsequent phases we'll do even more. So in terms of breadth yes, we have looked broadly at everything and em... but in terms of depth, we have not even scratched the surface.

143. TH: Now, talking of transportation, it's eh of a great concern to me, and I'm sure a whole lot of other people who come to the city. And recently you talked about the black cabs. How feasible will these 
be in Abuja?

The attitude of the host in the excerpt above depicts the relationship between Nigerian Government officials and journalists; a foreign host may not treat the minister in a similar manner. However, not minding the social status of the Governor of Lagos state in ND3 and that of Wole Soyinka in ND4, we had some interruptions from TH (6 in ND1 and 6 in ND4).

\section{Excerpt 8-ND3}

49.

50.

51.

52.

53.

54.

55.

56.
TH: That is it! (applause). So that, even, when children come from a very poor background the school is the thing that

PP: $\quad$ is well modeled, character is well modeled.

TH: ...Opens their eyes to complete different things. They would like to go out of their house

PP: $\quad$ and go to school

TH: incredible!

PP: $\quad$... In the same way you want to go to a good office........

TH: Hun, Hun, shining, bright office will full AC

PP: $\quad$. $\quad$ is the same way that kids would love to go to a very lovable school, that's the difference; it seems so simple but I think it will work

Perhaps one would assume that the interruptions above were possible because of the gender of TH. Could it be that females are bolder when discussing with highly placed guests than their male counterparts?

\subsection{Gender}

Another determinant of the features and patterns of turn-taking is the gender of the participants. West (1998), in her study of interaction between doctors and patients, came to the conclusion that status alone cannot account for dominance in conversations. She discovered that female physicians were interrupted more often by patients of all social status groups than male physicians. Male participants are also believed to take more turns than their female counterparts in discussions. Female participants are known to be more reserved; they only contribute when they are called to do so. However, we discovered that things have changed. Women took as many turns as men in Nigerian TV talk shows; they also did not hesitate to interrupt the male participants during discussions. This suggests that unlike in the days of Tannen (1983) and Zimmerman and West (1975) when women were observed to take passive roles in conversation, the issue of women liberation and gender equality have come to change things. Women are more learned and educated about topical issues; in fact, most of them occupy important positions in their professions. Thus it is impossible to relegate them to the background. Most hosts on TV talk shows invite them as special guests on their programmes. In PG3, Dr. Ifeoma Okoye, the then president of the Association of Radiologists of West Africa was allocated the first turn though she was a female:

\section{Excerpt 9-PG2}

8. TH:

...Dr Okoye, you are the current president of the association, you could just bring us up to book to where are we in that compared with South Africa and other parts of the world. Where are we in terms of being able to use the technology for the well-being of the average em Nigerian?

9. PP1:

Well (.) em... up till recently we've really been behind time so much so that at a time it was beginning to be difficult to read international journals. Em.... radiology and its practice in Nigeria was so well way back(.) about... em... five years ago, em... what we call computerized came to the country about 12 between hospital got there and that improved the practice of radiology, we are able to...

Dr Okoye interrupted the men about six times while the second female speaker also enjoyed freedom to the floor. She was in no way hindered by her sex. The two female participants in PG4 also participated actively. Cordelia had 8 turns while Njideka had 13 out of which 6 were successful interruptions.

In IO4, one out of the three female guests refused to be intimidated by men. Whenever she realised that the men would not want to give her the floor, she resorted to raising her voice. She successfully took the floor through interruption 8 times. 


\section{Excerpt 10-IO4}

3. PP1:

Agatha, I would say this, we are talking about emotion now we are not talking about love, you mentioned emotion.

4. PP3 (female): Love is an emotion, love is an emotion...

5. TH: $\quad$ Are you saying, wait, are you saying? Because if I should go by what you have just said...

6. PP1: what is obtainable in the whole world...

7. PP3 (female): He doesn't know all the women in the world, he doesn't know me and I don't know him okay?

Here, PP3 the most outspoken of the female guests refused to be dominated by the male participants. She took her stand by making sure that she also made her contribution when it was necessary. The other two female guests were not as active as the one discussed above. They only spoke when they were prompted. One of them even displayed some traits of timidity when she was asked to comment:

\section{Excerpt 11-IO4}

1. TH:

I still want to ask Glory that are you somebody that does not react to emotions and all of that

2. PP4(female): well...

3. TH: That should be easy for you to answer...

4. PP4(female): I will say yes because of things that happened...(she was interrupted)

The hesitations by PP4 above show that she lacked confidence in herself. It therefore indicates that not all Nigerian females have the boldness to exhibit confidence in a public gathering.

\subsection{Culture as a Determinant of Turn-taking Features}

Effective communication depends upon a shared understanding of behavioural cues. Moreover, the turn-taking rules are probably not generalisable to other cultures even if they are for our own culture (Larrue \& Trognon, 1993:27). In Nigeria, turns are pre-allocated according to age hence limiting the freedom of turn-taking. Elderly people speak uninterrupted by the younger people because elderly people control turn-taking. They seem to have the right to interrupt younger speakers at will. However, the opposite is the case in the relationship between the host and the participants (guests), especially in ND3 where Funmi had the Lagos State governor as her guest. It was a level playing ground. Disregarding age and social status, the host interrupted the guest at will though she was younger in age and lower in status, only in a few cases did the host allow the guest to finish his contributions. The guest too did not seem to mind the interruptions. The host is treated as equal in status and age. One reason that accounts for this is the use of English language. Perhaps if the L1 had been used as the language of the talk show, deference to age and social status would have been more obvious.

We can therefore conclude that unlike in casual conversations and classroom interaction, where a child is not expected to interrupt her mother, father or an elderly participant, culture does not play a prominent role in determining how turns are taken in Nigerian TV talk shows. One can then say that while turns are pre-allocated in casual conversations and classroom interactions, they are not pre-allocated in Nigerian TV talk shows. Age is not a licence to dominate talks in TV talk show; a talk show is a forum where everybody is placed on an equal footing. Reciprocal first name use is also prevalent in media interactions especially on Radio and Television. The host is referred to by his first name; sometimes the host also refers to participants by their first names or official titles.

The use of first names with relative strangers has been seen as part of the Americanisation of British culture and indicative of what Fairclough terms 'synthetic personalisation'- the seeming familiarity with groups of others with whom one is not acquainted (Fairclough, 1992 and Choulariaki and Fairclough, 1999). This 'synthetic personalisation' is part of a larger societal change which has been brought about largely through changes in commercial strategies within a multinational; global (i.e. American) capitalist phase in British culture (Hardt and Negri, 2000). We can also conclude from our findings that 'synthetic personalisation has crept into the language of the Nigerian media disregarding the place of the Nigerian cultures.

\section{Conclusion}

This paper examined peculiar factors that determine turn-taking patterns in Nigerian TV talk shows. From our findings we identified determinants such as the personality of the host, the social status of the participants, the composition of 
the guests including the studio audience, the duration of the programme, discourse topic, gender and culture. All these determinants played major roles in determining the patterns of turn-taking in our data. Controversial topics enjoyed more competition for the floor; thus there were more instances of interruptions and overlaps in PG1, PG4, IO1, IO3 and IO4. The village square sections of PG and IO4 which were made up of youths also had higher numbers of interruptions and overlaps because of the composition of the guests and studio audience, the effects of culture and gender on the patterns of turn-taking were also noticeable. Shows where there were differences in age and social status of the participants had fewer instances of interruption and overlaps. Almost all the turns were complete grammatical units. Speakers observed the turn-taking rules by waiting for the turn relevance place before taking their turns. We also observed that although gender had a role to play in determining the patterns of turn-taking in the shows examined, it was not to a great extent as things seemed to have changed as more women take up positions of responsibility.

\section{References}

Bente, G., \& Fromm, B. (1997). Affektfernsehen. Motive, Angebotsweisen und Wirkungen [Intimate television: Gratifications, formats, and effects]. Opladen, Germany: Leske \& Budrich. http://dx.doi.org/10.1007/978-3-322-91434-7

Berry, A. (1994). Spanish and American turn-taking styles: A comparative study. Pragmatics and Language Learning, monograph series, 5, 180-190.

Bosch, L., ten Oostdijk, N., \& de Ruiter, J.P. (2004). Durational aspects of turn-taking in spontaneous face-to-face and telephone dialogues. TSD, 563-570.

Chiluwa, I. E. (2005). Discourse pragmatics of news headlines and leadstories in Tell, The news and Newswatch, 1996-2002. PhD thesis, Dept. of English, University of Ibadan. xiii+212.

Chouliaraki, L., \& Fairclough, N. (1999). Discourse in Late Modernity: Rethinking Critical Discourse Analysis. Edinburgh: EUP.

Davis, S., \& Mares, M. (1998). Effects of talk show viewing on adolescents. Journal of Communication, 48(3), 69-86. http://dx.doi.org/10.1111/j.1460-2466.1998.tb02760.x

Edelsky, C. (1981). Who's got the floor? Language in Society, 10, 383-421. http://dx.doi.org/10.1017/S004740450000885X

Fairclough, N. (1992). Discourse and Social Change. Cambridge: Polity Press.

Goffman, E. (1967). Interaction ritual: Essays on face-to-face interaction. Oxford, England: Aldine.

Grindstaff, L. (2002). The Money Shot: Trash, class, and the making of TV talk shows. Chicago: University of Chicago Press. http://dx.doi.org/10.7208/chicago/9780226309088.001.0001

Hamo, M. (2006). Caught between freedom and control: 'ordinary' people are discursive positioning on an Israeli prime-time talk show. Discourse and Society, London, Thousand Oaks: Sage publications. Retrieved August 14, 2007 from http://das.sagepub.com at COMMUNICATIONS LIBRARY-FAX

Hardt, M., \& Negri, A. (2000). Empire. Cambridge MA, Harvard University Press.

Hua-Li Jian \& Wu Joyce. (2011). Mandarin conversation: Turn-taking cues in exchange structure. Proceeding from ICPhs XVII, Hong Kong, 17-21 Retrieved 7/23/2013

Jaffe, J., Beebe, B., Feldstein, S., Crown, C.L., \& Jasnow, M.D. (2001). Rhythms of dialogue in infancy: coordinated timing in development. Monographs of the Society for Research in Child Development, 66(2), 1-132. http://dx.doi.org/10.1111/1540-5834.00137

Jia L. (2010). Possible factors affecting women's conversational style -An investigation of hedges used by women in the American TV-series Desperate Housewives. English III, C-level Essay in English Linguistics. English Department Kristianstad University.

Laskowski, K., Ostendorf, M., \& Schultz, T. (2008). Modeling vocal interaction for text-independent participant characterization in multi-party conversation. Proc. SIGdial, 2008(June), 148-155.

Laskowski, K., Ostendorf, M., \& Schultz, T. (2007). Modeling vocal interaction for text-independent classification of conversation type. Proc. SIGdial, 194-201.

Odebunmi, A. (2003). Pragmatic features of English usage in hospital interactions amongst medical practitioners and 
patients in south-western Nigeria. Ph.D. Thesis. Department of English. Obafemi Awolowo University, Ile-Ife. xvii +310 .

Olutayo, O.G. (2010). Turn management in Nigeria television talk shows, 2004-2008. Ph.D. Thesis. Department of English. University of Ibadan, Ibadan. xiv +217.

Onadeko, T. (1999). A discourse analysis of conversational strategies in magistrate courts in Nigeria. Ph.D Thesis, Department of English. University of Ilorin, Ilorin. vi +284 .

Oyeleye, A. L., \& Olutayo, O. G. (2012). Interaction Management in Nigerian Television Talk Shows. International Journal of English Linguistics, 2(1), 149-161. http://dx.doi.org/10.5539/ijel.v2n1p149

Oyeleye, L., \& Osisanwo, A. (2013). Lexicalisation in Media Representation of the 2003 and 2007 General Elections in Nigeria. World Journal of English Language, 3(2), 1-9. http://dx.doi.org/10.5430/wjel.v3n2p1

Taiwo, R. (2008). Language, ideology and power relations in Nigerian newspaper headlines. Nebula: A Journal of Multidisciplinary Scholarship, 4(1), 218-245.

Tannen, Deborah. (1983). When is an overlap not an interruption? One component of conversational style. The First Delaware Symposium on Language Studies: Selected Papers, Robert J. Di Pietro, William Frawley \& Wedel Alfred, (Eds.) Newark: University of Delaware Press, 119-129.

West, C. (1984). Routine Complications. Troubles with Talk between Doctors and Patients. Bloomington, Indiana: Indiana University Press.

Zimmerman, D. H., \& West, C. (1975). Sex roles, interruptions and silences in conversation. In B. Thorne and N. Henley (Eds.) Language and Sex. Difference and dominance. Rowley, Mass: Newbury House, 105-29. 